Farum

Sociológico

\section{Forum Sociológico}

Série II

32 | 2018

Fraturas sociais e educativas: Desafios para a sociologia da educação

\title{
El absentismo escolar en contextos de vulnerabilidad social. Una reflexión antropológica
}

Absentismo escolar em contextos de vulnerabilidade social. Uma reflexão antropológica

School absenteeism in contexts of social vulnerability. An anthropological reflection

Juan Carlos Romero Villadóniga

(2) OpenEdition

Journals

Edición electrónica

URL: https://journals.openedition.org/sociologico/2044

DOI: $10.4000 /$ sociologico. 2044

ISSN: 2182-7427

Editor

CICS.NOVA - Centro Interdisciplinar de Ciências Sociais da Universidade Nova de Lisboa

Edición impresa

Paginación: 49-57

ISSN: 0872-8380

Referencia electrónica

Juan Carlos Romero Villadóniga, «El absentismo escolar en contextos de vulnerabilidad social. Una reflexión antropológica», Forum Sociológico [En línea], 32 | 2018, Puesto en línea el 16 julio 2018, consultado el 30 marzo 2022. URL: http://journals.openedition.org/sociologico/2044 ; DOI: https:// doi.org/10.4000/sociologico.2044 


\title{
EL ABSENTISMO ESCOLAR EN CONTEXTOS DE VULNERABILIDAD SOCIAL. UNA REFLEXIÓN ANTROPOLÓGICA
}

\author{
ABSENTISMO ESCOLAR EM CONTEXTOS DE VULNERABILIDADE SOCIAL. UMA REFLEXÃO \\ ANTROPOLÓGICA
}

\author{
SCHOOL ABSENTEEISM IN CONTEXTS OF SOCIAL VULNERABILITY. \\ AN ANTHROPOLOGICAL REFLECTION
}

Juan Carlos Romero Villadóniga

Grupo HUM 556 (Mundialización e Identidad), Universidad de Huelva, Espanã, \& IES La Marisma, Huelva, España

\begin{abstract}
Resumen
En una sociedad globalizada, donde el conflicto se entiende como una mera transgresión y no como una oportunidad para la reflexión y el cambio, las poblaciones de adolescentes en riesgo de exclusión social cada vez ven más limitadas sus posibilidades de acceso a la comunidad. Es entonces cuando el conflicto se convierte en violencia, pues las herramientas formativas han fallado en su primera concepción. Por esta razón, en la investigación se analizan cómo los mecanismos a través de los cuáles se lucha contra el absentismo escolar encierran, en ocasiones, violencias sistémicas y simbólicas hacia los sujetos. Para ello tomaremos como campo de trabajo uno de los escasos centros existentes en el territorio andaluz considerados como parte de el Programa Actuación Preferente, al trabajar prácticamente en su totalidad, con población en riesgo, lo cual le confiere un carácter especialmente relevante de cara al conocimiento de las dinámicas en las que se produce el absentismo escolar.
\end{abstract}

Palabras clave: problemas sociales, integración, complejidad, capital cultural

\section{Resumo}

Numa sociedade globalizada onde o conflito é entendido como uma mera transgressão e não como uma oportunidade de reflexão e mudança, as populações de adolescentes em risco de exclusão social estão cada vez mais limitadas no acesso à comunidade. É então que o conflito se torna violência, porque as ferramentas de treinamento falharam em sua primeira concepção. Por esta razão, a pesquisa examina como os mecanismos através dos quais a luta contra o absenteísmo escolar às vezes envolve a violência sistêmica e simbólica em relação aos assuntos. Para este fim, tomaremos como campo de trabalho um dos poucos centros no território andaluz considerado como parte do Programa Actuación Preferente, trabalhando praticamente na sua totalidade, com uma população em risco, o que Ihe confere um caráter particularmente relevante tendo em vista o conhecimento da dinâmica em que ocorre o absenteísmo escolar.

Palavras-chave: problemas sociais, integração, complexidade, capital cultural

\section{Abstract}

In a global and interdependent society, in which conflict is conceived as a mere transgression and not as an opportunity for self-reflection and change, youth populations at risk of social exclusion are increasingly aware of their limited or no access to the community. It is then that the conflict becomes violence due to the failure of the training tools in earlier stages of their development. For this reason, the present paper analyses the way in which all the mechanisms used to fight against school absenteeism hold out systemic and symbolic violence to individuals in many cases. To this end, our fielwork is focused on one of the few schools located in Andalusia that are considered to 
be part of a Preferential Intervention Programme by working almost entirely with population at risk. This fact grants it certain unique characteristics that make it ideal for exploring the dynamics of school absenteeism.

Keywords: social problems, integration, complexity, cultural capital

\section{Érase una vez un fenómeno denominado absentismo...}

El fenómeno del absentismo escolar, tanto en España como en el resto de la UE, es un tema que levanta pasiones, siendo prioritario en la agenda educativa (Glasman, 2003). Para Río Ruiz (2012), a pesar de ser un fenómeno que se encuentra en progresivo control y descenso, lo cierto es que es un tema de marcada actualidad debido a la visibilización del fenómeno en la sociedad española, al ser objeto de gran cantidad de programas y subvenciones públicas.

Es en esta abrumadora e ingente cantidad de noticias, cuando el fenómeno se torna en un hecho despersonalizado, algo abstracto que queda en unas simples cifras, o bien se llena de estereotipos en los cuáles se hace ver que el actual sistema en el que nos encontramos es el que está generando toda suerte de desdichas a sus ciudadanos. Sin embargo, en muy pocas ocasiones se plantea la necesidad de abordar el problema desde una óptica en la cual el sujeto absentista es parte de un problema, al tiempo que víctima de éste. Rara vez se apunta cómo la violencia que ejerce la sociedad hegemónica sobre estas culturas minoritarias deriva a procesos de resistencia, desarrollando una agencia excluyente en la cual se refuerzan los lazos con su comunidad de origen, frente a las imposiciones de una cultura externa.

Por esta razón, intentar abordar el fenómeno del absentismo requiere interpretarlo desde la intersección de gran cantidad de variables, algunas inherentes al propio sujeto, otras, como veremos a lo largo de estas páginas, al propio modelo educativo en el que se desarrolla la acción. $Y$ es que, aunque suene paradójico, medidas como la atención a la diversidad pueden encerrar el germen del abandono y el absentismo. La creación de centros educativos en zonas de actuación preferente, la imposición de modelos curriculares lejanos a los ejes de interés cultural del alumnado, o las políticas de seguimiento del absentismo, pueden ser caldo de cultivo para una potenciación de éste, especialmente en contextos de vulnerabilidad social.

El absentismo escolar tiene múltiples dimensiones e intersecciones, adoptando, igualmente, formas muy variadas. En este sentido, Blaya (2003) establece una tipología que no se aplica a la hora del análisis oficial de esta problemática. Así, se debe establecer una distinción entre un absentismo de retraso a determinadas horas, un absentismo de interior, también llamado por otros autores "virtual" (García, 2001), donde el alumno se encuentra sólo físicamente; absentismo elegido, donde se eligen a qué asignaturas acudir; absentismo crónico (itinerante o absoluto); así como absentismo justificado por el entorno familiar del alumno. Sea como fuere, lo cierto es que el resultado final del proceso va a ser el abandono educativo, que no absentismo (son dos cosas muy diferentes, aunque la una conlleve a la otra), el cual resulta alarmante en el contexto español.

De esta forma, el informe que elabora anualmente el Ministerio de Educación, Cultura y Deporte (2016), en adelante MECD, sitúa a España en cabeza del abandono educativo en la UE, estando tan sólo próxima Malta y Rumanía, aunque muy alejada de países como Francia (9,3\%), Finlandia $(9,2 \%)$ o Alemania $(10,1 \%)$.

Por comunidades (figura 1), nuevamente la brecha entre el Norte y el Sur se hace patente, apareciendo los mayores porcentajes en autonomías como Andalucía (24,9\%), Baleares $(26,7 \%)$ y las ciudades autónomas de Ceuta y Melilla $(26,9 \%)$.

Esta cantidad tan prolija de datos referentes al abandono escolar en España contrasta con el oscurantismo y vacío de información respecto al absentismo. Así, resulta muy frecuente meter en un mismo grupo a situaciones de riesgo escolar muy diferentes entre sí, aunque con un resultado común, el abandono del sistema educativo.

Igualmente, tampoco resulta infrecuente no disponer de datos concretos acerca del absentismo en determinadas comunidades (Río Ruiz, 2012), debido al secretismo existente por parte de la Administración Educativa. De esta forma, no existen, para el caso andaluz, estadísticas oficiales publicadas al respecto, habiendo un gran oscurantismo en lo referente a cifras, las cuales se aproximan al $25 \%$ que aporta la OCDE (2012), en el último estudio que pone en liza las ausencias de alumnado reconocidas por el mismo, frente al $28 \%$ unos años atrás, como pone el valor el informe PISA 2012, analizado en el estúdio de Afonso "La inteligência emocional", del año 2016.

A todo ello hay que sumarle la heterogeneidad en el sistema de recogida de faltas y tratamiento 
Figura $1 \triangleright$ Abandono educativo temprano por comunidad en 2015

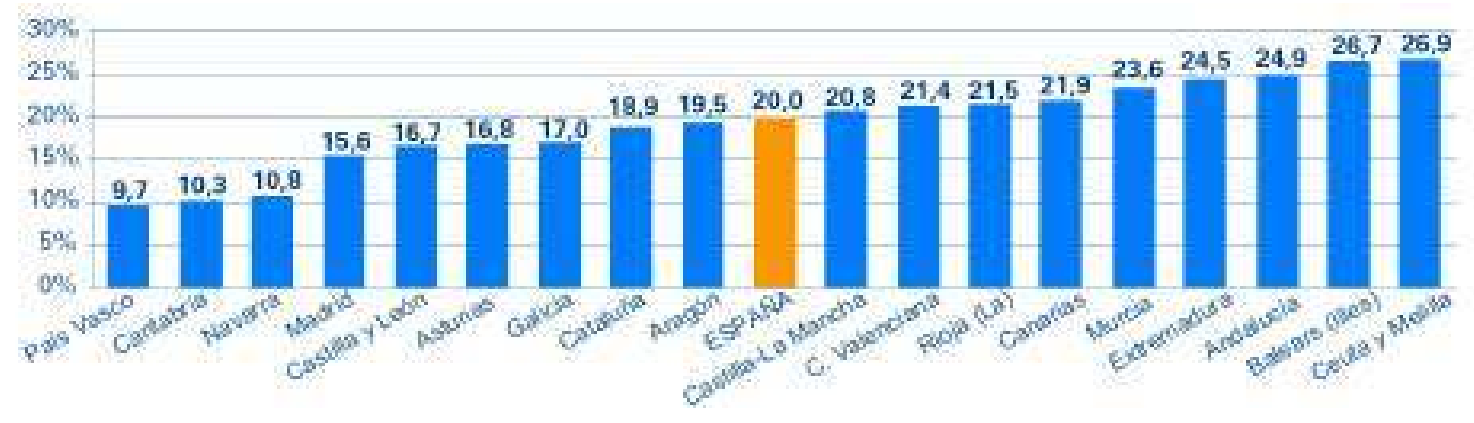

Fuente: Ministerio de Educación, Cultura y Deporte (2016).

de éstas (Río Ruiz, 2012), generando problemas de invisibilización de absentistas (García, 2005), especialmente en determinados contextos de actuación preferente donde el fenómeno alcanza dimensiones muy preocupantes.

Sea como fuere, lo cierto es la inexistencia de estudios globales que analicen las diferentes variables que intervienen en el fenómeno del absentismo, y más especialmente en contextos donde la vulnerabilidad social, con el estigma que trae aparejado, hace acto de presencia, generando profundas contradicciones entre el discurso teórico del sistema educativo y sus prácticas hacia los sujetos.

El triunfo de la sobremodernidad (Augé, 2008), ha provocado profundos cambios en las cotidianeidades y prácticas educativas. Ello ha generado una profunda transitoriedad e inestabilidad en el sistema educativo, convirtiéndose en una institución donde ha permeado el mundo líquido, como apunta Bauman (2007). Esta liquidez no afecta por igual a todos los colectivos, siendo el más vulnerable el que se encuentra en riesgo de exclusión social.

Estos canjes tan rápidos no se han visto acompañados de cambios igualmente notorios en el tratamiento de alumnado en situación de vulnerabilidad, con riesgo de absentismo y abandono del sistema educativo. En este sentido, a pesar de los denostados esfuerzos de la administración educativa, la realidad que rodea a este alumnado es la de desarrollar sus vivenciaciones y cotidianeidades en centros educativos donde se dan proyectos pedagógicos poco ajustados a la realidad tanto del docente como del discente, con un profesorado con gran dificultad de poder atender a una diversidad. Estas, que no son sino realidades cotidianas, como bien apuntan tantos autores (García Castaño y Olmos Alcaraz, 2012; Jociles y Franzé, 2008; Jociles, Franzé y Poveda, 2011; Soriano, 2009; 2011), genera una profunda brecha entre lo que el sistema ofrece y lo que reclama el sujeto.

\section{Nuestro campo de análisis. Aterrizando en un mundo multicultural}

La barriada Diego Sayago, también conocida como "El Torrejón", fue construida en 1977 a través del Instituto Nacional de la Vivienda, en el marco del Plan Municipal de Erradicación del Chabolismo. En sus primeros tiempos englobará a comunidades provenientes de áreas periféricas de la ciudad de Huelva, tales como Marisma del Odiel, Pilar de Balbueno y Chorrito, con un claro predominio de población gitana $(45 \%)^{1}$, las cuales se concentrarán en bloques de pisos contiguos, provocando la mezcla de clanes rivales y la generación de tensiones territoriales.

En sus primeros tiempos la barriada se ubicará en la periferia de la capital onubense, siendo un foco importante de marginalidad y exclusión social. Su población se definirá por presentar bajos niveles de alfabetización y cualificación profesional, dedicándose a la venta de chatarra principalmente al tiempo que, a la venta y consumo de drogas, suponiendo una profunda estigmatización de sus habitantes, los cuales verán limitados sus oportunidades de acceso al mercado laboral, especialmente la población de etnia gitana. Actualmente, los informes realizados desde la Comisión Distrito V (2016) nos informan de una barriada con graves precariedades sociales, presentando carencias de servicios.

En este contexto, el informe (Distrito V, 2016) perfila un alumnado que acude al IES La Marisma, el único centro público de Secundaria presente en la zona presenta, con unas características muy específicas:

- Desfase curricular significativo respecto a su grupo de referencia. De ellos, aproximadamente el $85 \%$ no ha adquirido ni consolidado los aprendizajes instrumentales básicos de lecto-escritura y cálculo.

- Alto porcentaje perteneciente a minoría étnica, sobre todo a la etnia gitana ( $80 \%)$, que dificulta su escolarización normalizada 
debido al nivel mínimo de competencia lingüística que le dificulta la comunicación y el acceso al currículum ordinario.

- Pertenencia a colectivos que presenta condiciones sociales desfavorecidas, que acude al centro sin los materiales necesarios para el aprendizaje.

Esta situación de partida hace que el absentismo se convierta en una de las principales problemáticas del centro, de ahí la importancia de su análisis.

\section{Metodología}

Los objetivos que han marcado la investigación han sido muy variados. De forma sintética cabrían destacarse:

- Establecer el perfil del alumnado absentista.

- Determinar la importancia del entorno social y académico en la producción de discursos y prácticas ligadas al fenómeno.

- Conocer la influencia de las violencias escolares sobre los sujetos.

- Reducir el nivel de absentismo mediante el conocimiento de sus dinámicas generadoras y la aplicación de programas preventivos.

Estos objetivos están inspirados en nuestra hipótesis de partida. Entendemos que el fenómeno tiene un fuerte componente social y cultural influyendo, aunque en menor medida, la capacidad de agencia del sujeto. La reducción de las violencias que ejerce el sistema sobre los sujetos se comporta como vital para la mitigación del fenómeno del absentismo, especialmente en contextos de vulnerabilidad social.

La etnografía escolar ha sido nuestra principal herramienta de análisis. La investigación se ha basado en el estudio combinado de técnicas cuantitativas y cualitativas. De las primeras, destaca el seguimiento de las diferentes casuísticas ligadas con el fenómeno del absentismo por medio de análisis estadísticos a partir de la introducción de variables objetivas en bases de datos, desde el año 2009. Análisis de las derivaciones al aula de guardia, causas que motivan la ausencia, así como la respuesta de las familias han sido algunos de los estudios realizados de forma casi continua. Sin embargo, las técnicas que han proporcionado una mayor cantidad de información han sido las de tipo cualitativo. Las entrevistas semiestructuradas llevadas a cabo (30) tanto a familias como alumnado y profesorado, realizadas todas ellas en horario escolar a lo largo de las diferentes campañas prospectivas, han resultado ser vitales. Igualmente, las observaciones recogidas a lo largo de nueve campañas de tres meses de duración, nos ha permitido tener una mejor aproximación al problema, facilitando una aproximación encarnada.

Los resultados de la etnografía no arrojan lugar a dudas. El fenómeno del absentismo es de tal envergadura, que reducirlo a una mera suma de sus partes genera una falsación del problema en su conjunto. Resulta necesario una aproximación holística al problema, ya que una aproximación únicamente culturalista no permite un conocimiento complejo del mismo. No obstante, para el caso que nos ocupa, éstos pueden ser agrupados para una mejor exposición de los mismos, en dos grandes conjuntos de factores, al objeto de facilitar su comprensión.

\section{Factores organizativos del sistema escolar}

El sistema escolar forma parte del problema, ya que un análisis en profundidad de los casos analizados nos informa acerca de graves contradicciones entre los discursos teóricos que se esgrimen, y las prácticas que se realizan, como bien apuntan autores como García (2001), Río Ruiz y Benítez (2009), Martínez, Giménez y Alfageme (2001) o Martín Criado (2010). En este sentido, la opacidad del tratamiento y difusión de la información (García, $2001 ; 2005)$, es un problema a tener en cuenta, ya que fomenta la invisibilización del fenómeno. Ésta provoca, entre otras cosas, el desconocimiento de las cifras salvo por contadas autoridades académicas (coordinadores de absentismo, equipos directivos de los centros y personal de alto rango de la administración), no pudiéndose dimensionar cuantitativamente el fenómeno, como bien apunta uno de los coordinadores en una charla informal mantenida al respecto:

¿Informes y estadísticas sobre absentismo escolar? Claro que tenemos. A mi cada año me facilita la Delegación un CD con todos los datos estadísticos de la zona, aunque por cuestiones de privacidad no salen nunca a la luz. Tan sólo las utilizamos aquellos que estamos en las comisiones de absentismo o tenemos relación con ella. Es un tema muy delicado y las cifras se deben analizar con mucho cuidado... (Conversación informal con miembro equipo, comunicación personal, 24 mayo, 2017)

Del mismo modo, el tratamiento meramente estadístico del tema, reflejado en cifras carentes de encarnación, sin tomar en cuenta el entorno socioafectivo y familiar del sujeto absentista, provoca una clara distorsión de los datos. Ello resulta más notorio cuando, debido a las actuales políticas encubiertas de segregación escolar a partir de las adscripciones residenciales, se generan verdaderos 
"guetos" educativos con un perfil de alumnado muy homogéneo, no ayudando a la inclusión de colectivos con problemas de integración escolar (Benito y González, 2007; El-Habib Draoui, Jiménez-Delgado, Ruiz-Callado y Jareño-Ruiz, 2016; García Castaño y Olmos Alcaraz, 2012). Así, el centro objeto de estudio presenta un perfil de alumnado de ESO y FPB con clara desventaja social, proviniendo la práctica totalidad de la misma barriada, con graves déficits sociales. Ello provoca una etnificación del centro, así como de las vulnerabilidades allí presentes, agravando con ello el fenómeno del absentismo.

Vamos a ver, uno de los grandes problemas que tiene los centros con gran cantidad de población absentista es la política de adscripción territorial. No se permite que se puedan mezclar los alumnos, y como sea una zona con problemas sociales, como es nuestro caso, problemas como el absentismo se generalizan y no nos dejan muchas herramientas para intervenir, porque la primera medida a tomar, y más importante, debería ser el poder dejar de ser un gueto educativo. (Entrevista con miembro de Equipo Directivo, comunicación personal, 8 marzo, 2017)

Esta política encubierta de "guetificación", provoca cambios y genera condicionantes en el resto de las estructuras organizativas del centro, al encontrarse con una realidad social y académica muy diferente del resto de los espacios educativos del entorno generando, de forma inconsciente, violencias simbólicas sobre los sujetos (familias y alumnado principalmente), al condicionar el absentismo a su condición social y no a una política educativa que reproduce las mismas desigualdades del sistema hegemónico.

Una de las consecuencias más inmediatas de esta política de "zonificación" del alumnado será la creación de un sistema de vigilancia y control muy sofisticado, así como de castigos sobre el sujeto absentista, alternando la vertiente punitiva al tiempo que la de asimilación de sujetos en palabras de sus profesionales "recuperable". Dentro del primer grupo, la creación de sistemas de control y protocolos contra el absentismo generará no pocas situaciones de conflicto entre todos los actores presentes en la acción educativa, especialmente entre familias y profesorado, ya que su inclusión dentro de los casos de la Comisión de Distrito de Absentismo puede derivar en la pérdida de derechos para el cobro de las asistencias sociales, como hemos recogido en numerosas ocasiones en nuestro cuaderno de campo:

Cuando me marcho del centro me encuentro un alboroto diferente al cotidiano. A Judith la han echado quince días por su mala conducta.
Ya en la calle observo cómo se acerca a su profesora a pedirle explicaciones, actuando ésta de forma seca, logrando de la alumna un gracias, me encanta estar quince días fuera de aquí, era justo lo que estaba buscando. Luego decís que falto, si cuando vengo me echáis pues prefiero no venir más. Si no fuera por la ayuda no me veríais más el pelo... (Diario de campo, comunicación personal, 24 de febrero, 2016)

La relación asimétrica generará espacios de resistencia y fronteras entre los sujetos, ya que lejos de solucionarse, se fomenta la creación de una ingente cantidad de absentistas virtuales los cuales acuden a las aulas, pero en una actitud de negativismo desafiante, repercutiendo en las relaciones del centro. Ello provoca conflictos y la generación de violencias multidimensionales (del sistema, simbólicas, microviolencias, brutalidades cotidianas), deteriorando la convivencia, al proyectarse sobre la alteridad las tensiones.

En esos momentos piden ayuda desde el aula de $1^{\circ}$ de ESO A. Al llegar me encuentro a Isabel en un rincón de su mesa abrazada a la caja donde se depositan los móviles. Junto a ella, amenazando se encuentra José, gritando e insultándola.

- José: Que me des el móvil, que me lo des o la vamos a liar...

En esos momentos empuja a la profesora y le arrebata la caja de los móviles, depositándola con violencia en el suelo. Coge su móvil y hace el intento de dar una patada a los restantes. Ante los requerimientos del jefe de estudios que ha llegado, sale de la habitación no sin antes tirar una bolsa con materiales con fuerza y propinar golpes a todo el mobiliario presente. (Diario de campo, comunicación personal, 4 de febrero, 2016)

Esta violencia sistémica provoca una desafección entre los integrantes del trinomio familias-alumnado-profesorado (Poveda, 2001), traduciéndose en un incremento del fenómeno del absentismo en sus múltiples variables, cobrando especialmente el de tipo selectivo, donde el alumnado selecciona las asignaturas a las que acude a partir de la afinidad existente con el docente. De esta forma, en no pocas observaciones recogidas, el alumnado establece estrategias de evasión frente aquellos profesores con los cuales no se establecen lazos afectivos, aspecto éste vital, como exponen autores como Railsback (2004), quejándose muchos alumnos de falta de conexión.

Había quedado con Enrique de $4^{\circ}$ para charlar sobre su futuro profesional. Se 
encuentra muy descorazonado y se plantea dejar los estudios:

- Enrique: Maestro, yo necesito motivarme, porque de lo contrario dejaré esto. A mí no me gusta estudiar ni me gusta lo que se enseña en el centro. He faltado algunos días y, entre eso y las pocas ganas que tengo de continuar me da miedo a abandonar.

Comienzo motivándolo, tocando el tema de la necesidad de terminar sus estudios para poder seguir ampliando sus conocimientos de bibliología, que es lo que realmente le gusta.

- Enrique: ¿Ves?, nada más hablarme de esas cosas me has convencido en la necesidad de continuar mis estudios y terminarlos para seguir con aquello que realmente quiero hacer. Es que me da pena que los otros profesores no quieran escucharme. Siempre me dicen que me deje de tonterías y haga únicamente lo que ellos quieran. (Entrevista con Enrique, comunicación personal, 4 de febrero, 2017)

La situación de tensión se agrava cuando entran en juego comunidades diferentes a la cultura hegemónica, provocando discontinuidades entre familias y escuela (Ogbu, 1982; Poveda, 2001), al manejar imaginarios muy diferentes entre sí, derivando todo ello en continuos problemas de percepción de la alteridad, como consecuencia de la entrada de valores los cuales distorsionan y vician la intersubjetividad.

A todos estos factores habría que sumarle otro de gran importancia, la existencia de dinámicas y contenidos dentro del aula que no favorece la motivación del alumnado. Constreñido por normas no interiorizadas, con unos contenidos alejados de sus centros de interés, se convierten en problemas más que ventajas, provocando un gradual distanciamiento entre lo que el sistema ofrece y las demandas de sus beneficiarios.

"Para mí es muy duro llegar cada día y estar frente a alumnos que no hacen nada, que sólo están ahí como quien dice para pasar el rato. Me siento frustrado, no tengo ganas de hacer nada con ellos" (Entrevista a profesor, comunicación personal, 20 de enero, 2016).

La respuesta de la administración educativa consistirá en la creación de todo un entramado de adaptaciones curriculares que no harán sino clasificar, catalogar y estereotipar a un alumnado ya de por si estigmatizado. Supondrá ligar el fracaso escolar, en este caso el absentismo, a su condición socioeconómica, generando un currículum oculto que precisamente reforzará la asimetría entre sujetos. Curiosamente, el fin último para el que se diseñó todo un entramado curricular, la "equidad en educación", no hará sino visibilizar la otra cara de la moneda, "la existencia de desigualdades en la acción educativa", en una liminalidad donde entrará en valor la cultura hegemónica frente a las de resistencia.

No es por lo que hicieran, sino por lo que no hacen. Están todo el día molestando, sin hacer nada, chabacanas como siempre. Están destrozando una clase donde no puedo hacer nada más que trabajar con fichas. iImagina en clase de ética trabajando sólo con fichas!, con la cantidad de posibilidades que tiene la asignatura...Y lo que más me jode no es eso, sino que veo que lo que hago vale una mierda. ¿De qué sirve que me esfuerce, tanta educación inclusiva si al final van a acabar vendiendo tomates?... lo que yo hago no vale un pimiento. (Entrevista con José, profesor, comunicación personal, 20 de enero, 2016)

Otros factores organizativos que van a entrar en juego en el absentismo escolar, tales como la departamentalización del centro (González, 2006), - la carga burocrática que debe padecer el profesorado, son elementos secundarios en el estudio de caso presente.

\section{La importancia del sujeto: Capacidad de agencia e intersubjetividad}

Un segundo grupo de factores, están referidos más a la complejidad del sujeto como ser social, y a su capacidad de agencia como motor para el impulso de inclusión en la comunidad. En este sentido, vamos a identificar tres grandes factores determinantes los cuáles hemos recogido en las diferentes etnografías llevadas a cabo.

El primero de los factores está delimitado por las oportunidades que se le ofrecen al sujeto, integrándose por dos componentes: la situación inicial de desventaja, interseccionada por otros factores como la edad, el sexo, género y origen étnico, al tiempo que las situaciones de exclusión promovidas por elementos tales como la estructura social, la precariedad económica, o la discriminación residencial. En este sentido, la gran mayoría de alumnado absentista recogido en la investigación presenta un mismo perfil socioeconómico, con graves carencias materiales y en una situación familiar de marcada precariedad. Así, el plan de actuación llevado a cabo por los servicios comunitarios de Distrito V (2016), apuntan a un perfil familiar del alumnado absentista en el centro que puede ser catalogado en situación de emergencia social, con elevados niveles de endeudamiento, alojadas en viviendas las cuáles son difíciles de mantener y con unos ingresos medios de unos $400 €$ provenientes de las ayudas sociales de instituciones y asociaciones. 
En este contexto de marcada vulnerabilidad social, buena parte del alumnado absentista adopta estrategias de supervivencia, alimentándose de forma irregular y con claras descompensaciones, siendo habitual la llegada de alumnado al centro que no ha ingerido alimento alguno desde el almuerzo de la jornada anterior, manifestándose en el rendimiento escolar:

Yo hay días que no puedo. A lo mejor he comido y luego no he cenado ni tampoco desayunado, o no he cenado y para desayunar me he tomado un trozo de pizza fría del día anterior. Luego pasa lo que me pasa, que me da un "chungo" en clases y los maestros me dicen "que si no me duerma, que si levanta la cabeza de la mesa". Si es que no puedo con el pellejo, como ellos vienen desayunados creen que todos lo podemos hacer. (Diario de campo, comunicación personal, 18 de febrero, 2016)

Esta situación genera conflictos con una parte del profesorado, quien recrimina la actitud de éstos, los cuales son tildados de "vagos" e "irresponsables", ante su predisposición al trabajo debido a la fatiga física, lo cual no hará sino empeorar el clima de convivencia, al tiempo que fomentará el absentismo. Estas diferentes apreciaciones debido a la existencia de imaginarios muy diferentes entre sí, se convertirá en una violencia simbólica hacia el alumnado, el cual acepta como propia esa situación y la interioriza, repitiéndose de forma cotidiana estas tensiones entre profesorado y alumnado.

Un segundo grupo de factores está compuesto por la existencia de diferentes normas de socialización presentes entre todos los actores educativos implicados. De esta forma, la práctica totalidad de alumnado tanto de centro, como incurrente en absentismo en sus diferentes modalidades, es de etnia gitana, quizás uno de los colectivos más vulnerables que hay a nivel educativo. La existencia de normas de socialización tan diferentes entre lo que la sociedad hegemónica impone, por medio de su cuerpo normativo, y los usos y costumbres que se enseñan desde su comunidad, genera un profundo abismo en el alumnado, el cual debe vivir entre dos contextos. Si a ello se le une la existencia de profundas discontinuidades entre las familias y el centro educativo (Poveda, 2001), el cual es visto como un elemento extraño a su cultura, se produce el caldo de cultivo propicio para generar una dinámica de resistencia entre ambas partes. Para el caso del sistema, esta resistencia se torna en violencia sistémica mediante la puesta en marcha de todo un aparato de control hacia los sujetos. Para el caso de las familias, la resistencia se manifiesta en situaciones como el abandono temprano del sistema, la escolarización tardía o el absentismo en sus múltiples variantes.

Yo para ir al centro y que me reciban como si mi hijo fuera un delincuente es que no voy. Soy gitana y lo llevo a mucha honra, y no me parece que no me comprendan a mi o a mi gente. Llegas y te están diciendo lo malo que hace tu hijo, cómo se comporta, pero muy pocas veces me dicen lo bueno de él, ique algo bueno tendrá supongo! Al final si lo echan diez días, diez días que descanso de preocupaciones, si es un mes, un mes. Estoy deseando que llegue la hora para quitarlo del colegio. (Entrevista a Soraya, madre, comunicación personal, 1 de abril, 2016)

La capacidad de agencia va a ser otro factor que resaltar respecto a la importancia del absentismo en el caso estudiado. En contextos de vulnerabilidad social, la agencia de los sujetos puede incidir de forma positiva o negativa, al determinar estrategias más o menos socializadoras. En el caso negativo, la agencia puede estar constreñida por las normas sociales de su entorno o la estructura que le rodea. Pero también puede ser un motor de cambio, al ejercer un empoderamiento en los sujetos, contrarrestando la influencia que pueden tener sobre ellos las normas sociales o el entorno (Pick, Sirkin, Ortega, Pavel, Martínez, Xocolotzim y Givaudan, 2007). Ello explica la existencia de cambios en los sujetos, o bien que, dentro de una misma unidad doméstica, la respuesta al fenómeno del absentismo sea muy diferente entre hermanos, haciendo ver la importancia de la agencia a la hora de entender este fenómeno:

Tanto mi hermano como yo hemos estudiado. Él hizo el ciclo de jardinería y yo, terminaré bachillerato y haré una carrera. Eso de que ser gitano o mestizo influye es, pero hasta cierto punto, porque yo lo soy y no por eso voy a dejar de estudiar y sacarme los estudios. (Entrevista a Isaac, comunicación personal, día 10 de marzo, 2015)

La capacidad de agencia va a conformarse en nuestra investigación, en otro factor explicativo que explica las múltiples dimensiones del absentismo, tomando como referencia la definición que hace de ésta Amartya Sen (1999). Este concepto comprende diferentes dimensiones las cuales se complementan entre sí: la autonomía, la autoeficacia, la autodeterminación, el autocontrol y la autorregulación. De la gestión que se haga de estas dimensiones se explican las derivas de los sujetos hacia la exclusión social o hacia la integración. 
Un análisis en profundidad de las estructuras organizativas del centro y de su entorno apuntan a la existencia de dinámicas, las cuales van reforzando la exclusión del sujeto absentista. En este sentido, la presión familiar y sus normas no suelen favorecer la inclusión del alumnado, al encontrarse en una liminalidad entre las tensiones de ambas instituciones. Ello provoca que las acciones y las estrategias que pueden desarrollar en su cotidianeidad queden limitadas por la acción de múltiples frentes, tomando las decisiones de forma extrínseca en la mayoría de las ocasiones, como respuesta a las necesidades de los demás y no en base a sus intereses.

Esta situación de vulnerabilidad hace que el sujeto no sea capaz de organizar su locus de control interno, creyendo en no pocas ocasiones, que la conducta propia no es importante, relegando su toma de decisiones en la alteridad, especialmente en su grupo de iguales, los cuales ejercen poder sobre él, relegando su capacidad de autorregulación en la decisión externa.

Yo te entiendo maestro, que no debo faltar al colegio. Pero si mis colegas me dicen de ir a parkour yo voy, porque para mí es más importante eso. Si no voy me dejan de lado y soy un "pringao", pero si falto al colegio me expulsáis unos días o una carta y asunto arreglado. Además, en la calle estoy mejor con mis colegas. (Diario de campo, Agustín, comunicación personal, 14 de febrero, 2017)

\section{Concluyendo... o quién sabe si comenzando}

A tenor de lo expuesto, podemos inferir la gran importancia que tiene la organización escolar, así como el contexto social en el que se desenvuelven las prácticas educativas, a la hora de la generación y/o explicación de fenómenos como el absentismo. Modelos curriculares alejados de los centros de interés del alumnado, aplicación de sistemas de control más punitivos que preventivos, la política de zonificación de centros, no son sino visibilizaciones de las violencias que desde el sistema se ejercen sobre los sujetos.

De esta forma, la política de asimilación del alumnado en riesgo de exclusión social, en sus múltiples variantes, esconde un currículum oculto en el que la jerarquía y la clasificación cobran un protagonismo estelar.

La importancia de la agencia va a resultar igualmente significativa para la casuística estudiada, así como la direccionalidad de la toma de decisiones del sujeto, eso sí, sin perder nunca de vista el contexto socioeconómico en el que desarrolla su cotidianeidad al tiempo que la cultura en la que se desarrolla su relación frente a la alteridad.
Como toda dialógica, también en la contradicción se encuentra el germen de una nueva conceptualización del problema. Y ante violencias sistémicas, la respuesta de la comunidad educativa debe girar alrededor de la necesidad de educar desde la interculturalidad, por medio de currículum adaptado a sus capacidades cognitivas, pero también a sus imaginarios y valores que los construyen como ciudadanos de pertenencia a un grupo o etnia. Al mismo tiempo, una mayor flexibilización en las políticas de medidas de atracción del alumnado absentista permite convertir los centros educativos en centros de atracción, en vez de ser percibidos como meras herramientas de control y castigo por parte de la sociedad hegemónica. Quizás este sea el reto inicial y final en contextos de vulnerabilidad social, la formación de sujetos con capacidad de autorreflexión y con agencias desarrolladas en vez de meros subproductos del sistema condenados a reproducir las asimetrías y la situación de desigualdad heredada de esta sociedad.

Para ello, es conveniente reconducir la concepción humana a su verdadero nivel de complejidad. Partir de la necesidad de asumir al sujeto como un ser en constante proceso dialógico y reflexivo que le empuja, de forma autónoma y libre, a una reformulación de su conciencia, constreñida por unas características sociales, biológicas y ambientales las cuales lastran su crecimiento y le impiden ser más autónomo. La clave de todo el proceso va a venir de la mano de la reflexividad (Pozzoli, 2006, p. 25). $Y$ en este sentido, quizás esta deba ser la dirección que deba tomar la educación del siglo XXI, como apunta Edgar Morin (1999), debiendo configurarse todo el entramado educativo hacia la consecución de un objetivo, la formación del ser humano en su complejidad y no como un mero subproducto para la reproducción del sistema.

\section{Notas}

1 Plan Municipal de Erradicación del Chabolismo de Huelva (Documento não publicado).

\section{Referencias bibliográficas}

Alfonso, E. (2016). La inteligencia emocional: Una herramienta clave para la motivación del estudiante y su rendimiento. Valencia: Servicio publicaciones VIU.

Augé, M. (2008). Los no lugares. Espacios del anonimato. Barcelona: Editorial Gedisa.

Bauman, Z. (2007). Los retos de la educación en la modernidad líquida. México: Editorial Gedisa.

Benito, R., y González, I. (2007). Processos de segregación escolar a Catalunya. Barcelona: Fundació Jaume Bofill.

Blaya, C. (2003). Absentéisme des élèves: Recherches internationales et politiques de prévention (Informe 
de investigación). Paris: Observatoire Européen de la Violence Scolaire, PIREF. Disponible en http:// www. recherche.gouv. fr/recherche/fns/blaya.pdf

Distrito V. (2016). Plan estratégico 2016/2020. Disponible en http://www.distrito5huelva.org/portal/ index.php/archivo/documentos/item/plan-estrategico-2016-2020

El-Habib Draoui, B., Jiménez-Delgado, M., Ruiz-Callado, R., y Jareño-Ruiz, D. (2016). Composición escolar y expectativas del alumnado por origen y etnia: Una aproximación a la segregación escolar extraoficial. RASE, 9(1), 59-77.

García Castaño, F. J., y Olmos Alcaraz, A. (2012). Segregaciones y construcción de la diferencia en la escuela. Madrid: Editorial Trotta.

García, M. I. (2001). L'absentisme escolar en zones especialmente desafavorides. El caso de la ciutat de Barcelona (Tesis doctoral). Universitat Autònoma de Barcelona, Facultat de Ciències Polítiques i Sociologia, Departament de Sociologia, Barcelona, España.

García, M. I. (2005). Culturas de enseñanza y absentismo escolar en la enseñanza secundaria obligatoria. Estudios de casos en la ciudad de Barcelona. Revista de Educación, (338), 347-374.

Glasman, D. (2003). Quelque sac quis d'un programme de recherche sur la déscolarisation. Ville-Ecole-Intégration Enjeux, (132), 8-18. Disponible en http:// www2.cndp.fr/revuevei/132/00801811.pdf

González, M. T. (2006). Absentismo y abandono escolar: Una situación singular de la exclusión educativa. Reice. Revista Electrónica Iberoamericana sobre Calidad, Eficacia y Cambio en Educación, 4(1), 1-15.

Jociles, M. I., y Franzé, A. (Eds.) (2008). ¿Es la escuela el problema?: Perspectivas socio-antropológicas de etnografía y educación. Madrid: Editorial Trotta.

Jociles, M. I., Franzé, A., y Poveda, D. (Eds.) (2011). Etnografías de la infancia y de la adolescencia. Madrid: Editorial Catarata.

Martín Criado, E. (2010). La escuela sin funciones: Critica de la sociología de la educación critica. Barcelona: Editorial Bellaterra.

Martínez, M., Giménez, A., y Alfageme, A. (2001). La situación escolar de la infancia gitana y el absentismo. Comunicación presentada en VII Congreso Español de Sociología, Salamanca, España.
Ministerio de Educación, Cultura y Deporte. MECD. (2016). Datos y cifras. Curso escolar 2016/2017. Madrid: MECD.

Morin, E. (1999). Los siete saberes necesarios para la educación del futuro. Madrid: Santillana.

OCDE. (2012). PISA 2012. Informe español. Madrid: MECD.

Ogbu, J. (1982). Cultural discontinuities and schooling. Anthropology and Education Quarterly, 13 (4), 290-307.

Pick, S., Sirkin, J., Ortega, I., Pavel, O., Martínez, R., Xocolotzim, U., y Givaudan, M. (2007). Escala para medir agencia personal y empoderamiento (ESAGE). Revista Interamericana de Psicología, 41(3), 295-304. Disponible en http://pepsic. bvsalud.org/pdf/rip/v41n3/v41n3a04.pdf

Poveda, D. (2001). La educación de las minorías étnicas desde el marco de las continuidades-discontinuidades familia-escuela. Gazeta de Antropología, (17), s/p. Disponible en http://hdl.handle. net/10481/7491

Pozzoli, M. T. (2006). El sujeto de la complejidad. La construcción de un modelo teórico transdisciplinar (eco-psico-socio-histórico-educativo). Polis. Revista de la Universidad Bolivariana, 5(15), 1-14.

Railsback, J. (Ed.) (2004). Increasing student attendance: Strategies from research and practice. Portland, Oregon: Northwest Regional Educational Laboratory. Disponible en http://educationnorthwest.org/sites/default/files/increasing-studentattendance.pdf

Río Ruiz, M. A. (2012). Entre las ausencias y las rupturas escolares: Condicionantes de las intervenciones frente al absentismo y sus efectos sobre las dinámicas de aulas y centro. RASE, 5(2), 186-204.

Río Ruiz, M. A., y Benítez, J. (2009). Intervención socioeducativa y confirmaciones familiares alejadas de la norma escolar. Sevilla: Fundación Centro de Estudios Andaluces. Disponible en http://www. centrodeestudiosandaluces.es/bibdigital/registro/ ficha. php? informatico $=00004764$

Sen, A. (1999). Nuevo examen de la desigualdad. Madrid: Editorial Alianza.

Soriano, E. (2009). Vivir entre culturas: Una nueva sociedad. Madrid: Editorial La Muralla.

Soriano, E. (2011). El valor de la educación en un mundo globalizado. Madrid: Editorial La Muralla.

Recebido a 28/08/2017. Aceite para publicação a 21/11/2017.

Juan Carlos Romero Villadóniga (jucarovi66@gmail.com). Grupo HUM 556 (Mundialización e Identidad), Universidad de Huelva, Espanã, \& IES La Marisma, Huelva, España. C/ Camilo José Cela 40-10 C, 21610- San Juan del Puerto (Huelva), España. 